\title{
Application of a Force Model Adapted for the Precise Turning of Various Metallic Materials
}

\author{
Richárd Horváth* - Judit Lukács \\ Óbuda University, Donát Bánki Faculty of Mechanical and Safety Engineering, Hungary
}

The knowledge of cutting forces is critical. They might affect the load of the machine and, in the case of fine turning, the deformation of thin and slim workpieces. The generated forces depend not only on material properties (hardness, tensile strength) and on cutting parameters, but also on the tool edge geometry, that strongly determines the geometry of the chip (thickness and width). This article deals with the application of a force model adapted for precise turning technology. Three different types of materials widely used in mass production were taken into consideration (C45 and K036 steel types and AS12 die-cast aluminium alloy). The components of cutting force were measured in three directions $\left(F_{c}, F_{f}, F_{p}\right)$ and the specific cutting forces were calculated. The main values of specific cutting forces were introduced for precision turning $\left(k_{1,0.1}\right)$; using this, a new force model was constructed based on the theoretical parameters of the non-deformed chip cross-section ( $h_{\text {eq }}$ is equivalent chip thickness and $l_{\text {eff }}$ effective length of the edge of the tool) in case of all three examined materials. Investigations revealed that the influence of $I_{\text {eff }}$ on specific cutting force components is not negligible; however, it has the least effect on $k_{c}$ and is the most influential in case of $k_{p}$. The errors of the constructed new force models follow Gaussian distribution with low values of standard deviation. Thereby, the models can be applied to estimate cutting force components during the technological process planning procedure with adequate accuracy.

Keywords: fine turning, force model, force measurement, specific cutting force

Highlights

- New predictive models were determined to estimate cutting force components while fine turning.

- $\quad$ Novel geometric parameters of the chip cross-section were introduced.

- The main values of specific cutting forces characterizing fine turning technology were theoretically calculated.

- The applicability of the equations for each material used was investigated by residuals.

\section{INTRODUCTION}

The cutting force has a significant effect on the geometry and tolerances (e.g. circularity, deviation of circular shape or cylindricity, ovality, conical surfaces) of the workpiece (especially in the case of thin and slim parts), which are key criteria for the products. Moreover, they also affect the tool wear process. Due to the development of technology, the new tool (coatings) and workpiece materials require the exact knowledge of the cutting forces, their investigation during turning is an important field of cutting studies. In the case of turning, the kinetic conditions of which can be seen in Fig. 1, a spatial force system is generated.

A new frictional model was constructed by Rusinek et al. [1] in case of orthogonal cutting that took the forces acting on the tool face as well as on the tool flank into consideration. Furthermore, the influence of the tool flank forces on system dynamics was studied.

The mathematical modelling of cutting processes can be based on two methods: creating mechanical or phenomenological models. In recent years, several researchers have investigated the machinability of different types of materials, dealt with optimizing, measuring, and calculating cutting forces.

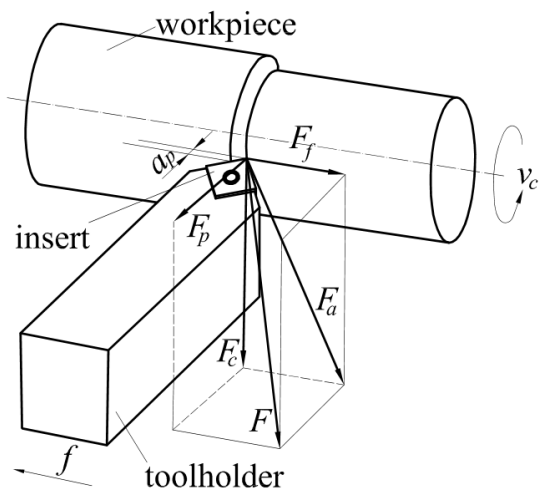

Fig. 1. The kinetic conditions of turning and the generated spatial force system

The investigation of the machinability of different types of steel is still a basic field of cutting studies.

Kulkarni et al. [2] carried out cutting tests on AISI304 austenite stainless steel by using AITiCrN coated inserts. In their experimental runs, the depth of cut was held at a constant value $\left(a_{p}=1 \mathrm{~mm}\right)$, the limits of the other cutting parameters were $v_{c}=140 \mathrm{~m} / \mathrm{min}$ to $320 \mathrm{~m} / \mathrm{min} ; f=0.08 \mathrm{~mm}$ to $0.26 \mathrm{~mm}$. The generated forces and the cutting temperature were studied. They said that regarding the force components, the effect of the feed was the most significant; however, the influence of cutting speed was negligible. In contrast, 
that was the cutting speed had the greatest impact on the value of the cutting temperature.

Čep et al. [3] investigated the machinability of $13 \mathrm{MoCrV} 6$ and $\mathrm{C} 45$ steels with two different types of Si3N4 based ceramic inserts (Tungaloy: FX105, CX710) in the case of interrupted machining.

Suresh et al. [4] examined the generated forces on AISI4340 steel with CVD coated (TiC/Ti/CN/ $/ \mathrm{Al}_{2} \mathrm{O}_{3}$ ) inserts. They created linear equations on calculating the resultant cutting force and the specific cutting force. The feed was declared to be the most significant factor, and the depth of cut was at the second position; however, the cutting speed was the least influential regarding the cutting forces.

López de Lacalle et al. [5] carried out high-speed milling cutting studies on inclined surfaces. Two types of steels (hardness: 30 and 50 HRC) were investigated when using sintered tungsten carbide ball end mills with TAIN coating. It was stated, that upmilling produces smaller deflection errors than downmilling does. In addition, average surface roughness values were higher in the case of $50 \mathrm{HRC}$ steel. Moreover, average surface roughness slightly increased with slope.

Cukor and Jurković [6] tested the cutting ability of DIN Ck45 steel in the case of dry turning with coated tool. Cutting forces, surface roughness, and tool wear were measured as a function of cutting parameters $\left(v_{c}, f, a_{p}\right)$. They determined a context among the set cutting parameters and the measured ones with the help of a genetic algorithm.

Multi-objective optimization is a key industrial question. Singaravel and Selvaraj [7] studied the problem mentioned in the case of turning EN 25 steel with coated carbide tools. Two methods (technique for order preference by similarity to ideal solution (TOPSIS) and analytic hierarchy process (AHP)) were combined to simultaneously minimize the microhardness and surface roughness of the cut surface and to maximize the material removal rate. Nevertheless, their combined method (TOPSIS and AHP) could determine the optimum cutting parameters.

Selvaraj et al. [8] examined two types of duplex stainless steel (DSS ASTM A 995 grade 5A - hardness: $223 \mathrm{HB}$ and grade 4A - hardness: 212 $\mathrm{HB})$ in case of dry turning. Feed and cutting speed were varied; in contrast, depth of cut was chosen to be held at a constant value. The influence of cutting parameters was measured on the generated forces, cut surface roughness, and tool wear. It was stated that feed is the most important factor in case of cutting forces and surface roughness (to an extent depending on the workpiece material); in contrast, cutting speed was found significant only in the case of tool wear. Optimum cutting parameters were determined for both materials, for which cutting forces and surface roughness were minimized.

Puh et al. [9] also defined the optimal parametric combination for turning processes. Their experiments were carried out on Ck45 steel with coated carbide insert under dry conditions. The Grey-Based Taguchi method was applied to minimize average surface roughness and to maximize material removal rate. It was stated that the cutting speed and depth of cut were two parameters significantly influencing the Grey relational grade. In addition, the depth of cut was the most effective factor in the performance.

Hassine et al. [10] presented a further multiobjective optimization in turning. The objective functions of their case study were to minimize production time, cost, and energy consumption.

Hard turning (turning of hardened steel types) requires special technology and tools. Carrying out studies in that field is currently very popular.

Karpuschewski et al. [11] analysed the influence of the microgeometry of the tool-on-tool wear in the case of hard turning. They used two types of ceramic insert (TiN coated and non-coated ones). Pairs of cutting speed-feed values were defined based on the measured force components $\left(F_{c}, F_{f}, F_{p}\right)$ to prevent tool edge chipping and sudden loss of cutting performance.

Nayak and Sehgal [12] investigated the machinability of AISI D6 (54 \pm 2 HRC) steel while hard turning. Their experiment was carried out by using three types of CBN tools. During the experimental runs, the main cutting force, the thrust force, the temperature of the edge of the tool, and the cut surface roughness were measured. Regarding the value of the main cutting force, the influence of feed was the most significant; however, the effect of cutting speed was declared infinitesimal.

El Hakim et al. [13] carried out cutting studies on a high-alloy tool steel (AISI T15; hardness: $\approx 52 \mathrm{HRC}$ ) using a multilayer coated ( $\left.\mathrm{TiC} / \mathrm{TiCN} / \mathrm{Al}_{2} \mathrm{O}_{3}\right)$ tool by hard turning. It was argued that over a certain cutting speed $\left(v_{c} \approx 40 \mathrm{~m} / \mathrm{min}\right)$ the cutting force components barely depend on the cutting speed (the values are a bit lowered because of the annealing caused by the high cutting speed).

Kundrák et al. [14] examined the change of the microhardness of the hard-turned cut surface. As the literature showed, the values of the cutting force do not directly influence the hardness of the cut surface. However, indirectly, by the transformation of the mechanical energy into thermal energy, the generated forces affect the hardness of the surface. 
Chen et al. [15] cut GCr15 (hardness: 60 HRC) bearing steel. In their tests, the values of cutting speed and feed were varied; however, depth of cut was held constant. All three force components were measured. It was determined that feed was the most significant factor on the values of the force and on the surface roughness. Having raised the value of feed, both these parameters had increased.

Meddour et al. [16] examined AISI 52100 steel (hardness: $59 \mathrm{HRC}$ ) in the case of hard turning. Ceramic inserts were used with different values of nose radius. Their studies were focused on the cutting forces and the cut surface roughness. An empirical model was created in order to estimate the cutting forces as a function of the systematically varied cutting parameters. Regarding the generated forces, depth of cut was the most significant factor; feed was also important. In contrast, the effect of cutting speed was negligible.

Wojciechowski et al. [17] examined ball-end milling of hardened steel $(55 \mathrm{NiCrMoV} 6$ - hardness: $\sim 55$ HRC). A monolithic sintered tungsten carbide ball end mill with TiAlN coating was chosen to study cutter's displacements and cutting force components in case of different surface inclinations $\left(0^{\circ}, 30^{\circ}, 60^{\circ}\right)$. The increased values of both feed per tooth and depth of cut resulted in higher values of cutting forces and tool's deflections. Nevertheless, in the case of lower values of cutting parameters, meaning smaller crosssections, maximal normal force was significantly lower. In addition, maximal normal force was higher when slot milling than when upward ramping $\left(60^{\circ}\right)$.

Moreover, the generated edge forces were analysed by Wojciechowski et al. [18] in case of ball milling of hardened steel (55NiCrMoV6). Monolithic sintered carbide ball end mills with TiAlN were used. The effect of surface inclination and progressive flank wear on edge forces was examined. It was proved that uncut chip thickness had the greatest influence on edge forces. During use, worn tool radial forces are higher than tangential ones. Regarding surface inclination, the highest force components were detected in the case of slot milling.

Further cutting studies [19] were carried out in case of cylindrical end milling of the same material. Monolithic tools were used with TiAlN coating. Cutter's displacements resulted from radial run out that is also generated by cutting forces. Radial run out was measured off-line. The model, developed for estimating surface roughness parameters, included dynamic tool displacements. Two different mechanisms of surface irregularity formation were determined.
An example of hard turning technology and its power relations is shown by Zębala and Kowalczyk [20] by using a polycrystalline diamond tool (PCD). Three different types of raw materials were investigated, the difference in whose was the amount of Co (10, 15, and 25 volume \%). In the cases of being alloyed with 15 and 25 volume \% Co, no significant deviation was found regarding the cutting forces.

As engineering plastics (non-reinforced and reinforced ones, as well polymer composites) are gaining popularity, several researchers are testing their machinability.

Mata et al. [21] were studying the cutting ability of polyether ether ketone (PEEK) reinforced with 30 $\%$ carbon fibre.

Hanafi et al. [22] also examined PEEK CF30. Dry turning conditions and TiN coated insert were chosen. In their experiments both three components of the cutting force were measured, the resultant cutting force and the specific forces were calculated. Empirical models were generated for the calculated values with the help of response surface methodology (RSM) and fuzzy algorithm. The application of the methods was compared.

Fetecau and Stan [23] turned two types of polytetrafluorethylene (PTFE) based composites: PTFE CG 32-3 (32\% carbon, $3 \%$ graphite) and PTFE GR 15 (15\% regenerated graphite). In their experimental runs, cutting parameters $\left(v_{c}, f, a_{p}\right)$ were changed; furthermore, three polycrystalline diamond tools (PCD) were used having different nose radii. It was stated that the generated forces depend primarily on feed and depth of cut; however, the main cutting force gives a nearly constant value as a function of cutting speed and tool nose radius. In the case of each material, predictive models were defined, consisting only of the main effects.

The application of light metals, as a reason of their advantageous qualities, is showing a growing trend in the past decades. The investigation of these materials and their alloys is an important research field.

Joardar et al. [24] dry turned SiC metal matrix composites with a PCD tool. An empirical model was determined to estimate cutting forces, in which not only cutting parameters were input parameters but also the amount of $\mathrm{Si}$.

Çolak [25] determined optimum cutting parameters of turning of Ti6Al4V titanium alloy with conventional and high pressure assisted cooling conditions by a genetic algorithm. The optimization was carried out with empirical equations regarding three factors: cut surface roughness, material removal 
rate, and machining performance. Tool wear was also examined. The longest tool life resulted from the highest cooling pressure.

De Augustina et al. [26] carried out turning studies on aluminium alloy UNS A97075 under dry conditions. Having used tools with different nose radii, cutting force components were measured. It was stated that in the case of low feed values both tools provided similar forces.

Horváth et al. [27] dealt with the machinability of aluminium in the case of fine turning. The cutting ability of two types of widely used dye-cast alloys (AS12 - eutectic and AS17 - hyper-eutectic alloys) was investigated by using five different diamond tools. Phenomenological models were generated to estimate surface roughness, depending on input cutting parameters $\left(v_{c}, f, a_{p}\right)$, as well as on workpiece and tool edge materials as qualitative factors [28]. In contrast, the statistical parameters of cut surface roughness (Rsk - skewness; $R k u$ - kurtosis) were examined. It was stated that those are independent of cutting parameters and are only functions of the tool edge geometry [29]. In addition, a dynamometer was constructed especially for measuring small force components $(0 \mathrm{~N}$ to $100 \mathrm{~N})$ [30]. A new force model for fine turning was also determined [31].

Regarding non-conventional cutting technologies, it is very important to know cutting forces and be able to typify them exactly.

Venkatesan et al. [32] give an overview of laser assisted machining (LAM) and disclose some options of the future development of the technology. Using the method of localized heating, cutting forces and tool wear can be reduced, however the quality of the surface and the amount of the removed material can be increased.

Further investigations are needed to determine cutting forces if kinematic, geometrical, and technological relations differ from conventional longitudinal turning.

Kundrák et al. [33] made an analysis of rotational turning (where an extremely high material removal rate can be achieved). Geometrical parameters of chip cross-section and cutting parameters were defined.

As mentioned above, in recent years, several researchers dealt with generating predictive models in order to estimate cutting forces. A wide range of methods was applied: creating linear equations, empirical models, using genetic algorithms, fuzzy logic, and the response surface method. In contrast, only a few studies provided mathematical formulae for predicting all three force components. Furthermore, most of the models operated with cutting parameters, raw material, etc.

In contrast to these studies, in this article, the authors show the application of a force model adapted for precise turning when the chip removal process primarily befalls on the tool nose radius. Consequently, novel geometric features of the nondeformed chip cross-section were introduced $\left(h_{e q}\right.$ and $l_{\text {eff }}$ ), based on both cutting parameters $\left(a_{p}, f\right)$ and tool geometry $\left(\kappa_{r}, r_{\varepsilon}\right)$. With the help of these parameters, equations were developed to estimate cutting force components $\left(F_{c}, F_{f}, F_{p}\right)$. However, the models are based on the widely known Kienzle-Victor formula [34], by $h_{e q}$ and $l_{\text {eff }}$ the characteristics of precision turning are taken into consideration. The applicability and expansibility of the new force model adapted for fine turning were proved in the case of three different types of raw materials (C45 - non-alloy steel, KO36 - stainless steel, AS12 - die-cast eutectic aluminium alloy).

\section{MATERIALS AND METHODS}

\subsection{Materials Used}

The experimental runs were carried out on three widely used materials those technological properties are however significantly different.

A generally used non-alloy steel $(\mathrm{C} 45,1.0503)$ was chosen that is appropriate for heat treatments. It is a material for products (vehicular and other engineering parts) being loaded with low and medium stress (tools, wear-proof parts). The chemical composition in weight $\%$ is the following: $\mathrm{C}=0.42$ to $0.5 ; \mathrm{Si} \leq 0.4 ; \mathrm{Mn}=0.5$ to $0.8 ; \mathrm{P} \leq 0.045 ; \mathrm{S} \leq 0.045 ; \mathrm{Cr}$ $\leq 0.4 ; \mathrm{Mo} \leq 0.1 ; \mathrm{Ni} \leq 0.4 ; \mathrm{Cr}+\mathrm{Ni}+\mathrm{Mo} \leq 0.63$.

The second material was an austenite stainless steel (KO36, 1.4541), which is one of the most widely used materials in the industrial technology because of its excellent weldability and machinability. It is typically used for products those face an increased level of mechanical and chemical load (food-, milkand chemical industry, containers, bottles). Moreover, the arms and aerospace industries use the alloy. The chemical composition in weight $\%$ is: $\mathrm{C} \leq 0.8 ; \mathrm{Si} \leq 1$; $\mathrm{Mn} \leq 2 ; \mathrm{Cr}=17$ to $19 ; \mathrm{Ni}=9$ to 12 .

Finally, our experiments were carried out on a die-cast eutectic aluminium alloy (AS12) that has excellent mechanical and technological properties moreover, its castability is quite good. Its typical areas of use are vehicular and engineering mass products. AS12 is composed of: $\mathrm{Si}=12.2$ to $13.2 ; \mathrm{Fe}=0.35$ to 
$0.55 ; \mathrm{Cu} \leq 0.04 ; \mathrm{Mn} \leq 0.09 ; \mathrm{Mg} \leq 0.04 ; \mathrm{Ni} \leq 0.04 ; \mathrm{Zn}$ $\leq 0.09 ; \mathrm{Ti} \leq 0.09$ in weight $\%$.

\subsection{Tools Used}

The non-alloy steel (C45) was cut with a CVD-coated (TiN/TiCN/Al2O3/TiN) carbic insert. Code: DCMT 11T304 FG TT8115 CVD, manufacturer: TaeguTec. In the case of the stainless steel (KO36), a non-coated CerMet insert was used. Code: DCMT 11T304 PC CT3000, manufacturer: TaeguTec. The cutting studies of the die-cast aluminium alloy (AS12) were carried out with a non-coated sintered carbide insert (Code: DCGT 11T304 FL K10, manufacturer: TaeguTec).

\subsection{Machines, Devices Used}

Cutting tests were carried out on a Dugard Eagle BNC $1640 \mathrm{CNC}$ lathe $\left(P_{\max }=11 \mathrm{~kW}\right.$, spindle speed: 100 $1 /$ min to $45001 / \mathrm{min})$. The cutting force components were measured by a dynamometer system which is based on a modified tool holder (its exploded view is shown in Fig. 2), developed by the author [30] especially in order to be able to determine the cutting forces during fine turning those are expected to be relatively small. The tool holder that is suitable to measure each force component was combined with a KISTLER 5019 Multichannel Charge Amplifier. The sampling rate was $2000 \mathrm{~Hz}$. The sensitivity of the constructed dynamometer (see Fig. 2.) depending on the directions of the measured force components are: $-3.463 \mathrm{pC} / \mathrm{N}$ for $F_{c} ;-7.47 \mathrm{pC} / \mathrm{N}$ for $F_{f}$ and -7.05 $\mathrm{pC} / \mathrm{N}$ for $F_{p}$. The exact values of the cutting forces were evaluated by DynoWare Software.

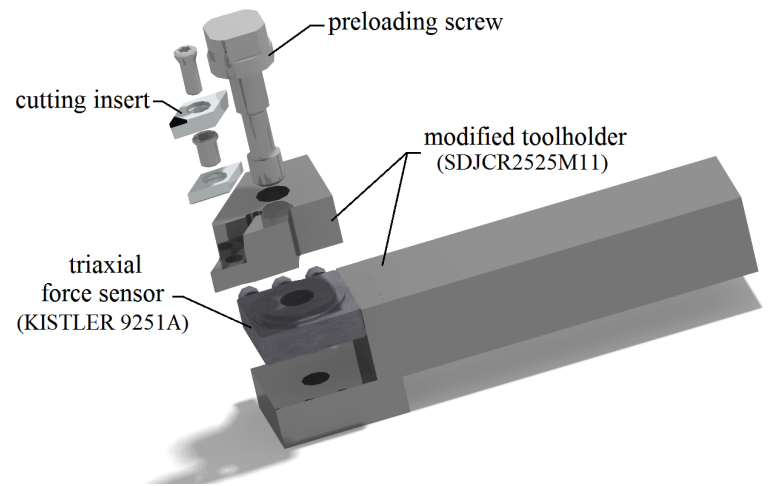

Fig. 2. The layout of the force measurement system [30]

\subsection{Force Model Adapted for Fine Turning Technologies}

A widely, even in industrial estimations used force model is the Kienzle-Victor equation, Eq. (1) [34] that is based on the geometrical parameters of the chip cross-section (chip thickness and width, see Fig. 3).

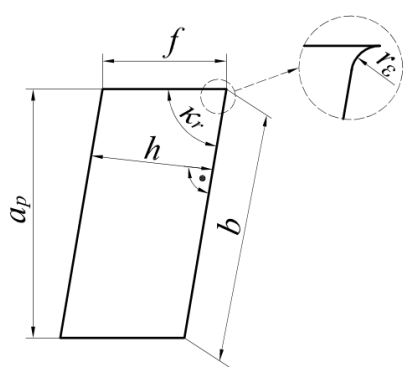

Fig. 3. Chip cross-section for the Kienzle-Victor model

Those can be easily calculated from the feed, the depth of cut and the side cutting edge angle (see Eqs. (1) and (2)). The removed chip cross- section can be defined by Eq. (3).

$$
\begin{gathered}
b=\frac{a_{p}}{\sin \kappa_{r}}, \\
h=f \cdot \sin \kappa_{r}, \\
A=a_{p} \cdot f=b \cdot h .
\end{gathered}
$$

In the Kienzle-Victor model, specific cutting force was introduced (in the direction of the main cutting force) as the ratio of the main cutting force and the removed chip cross-section (see Eq. (4)).

$$
k_{c}=\frac{F_{c}}{A} .
$$

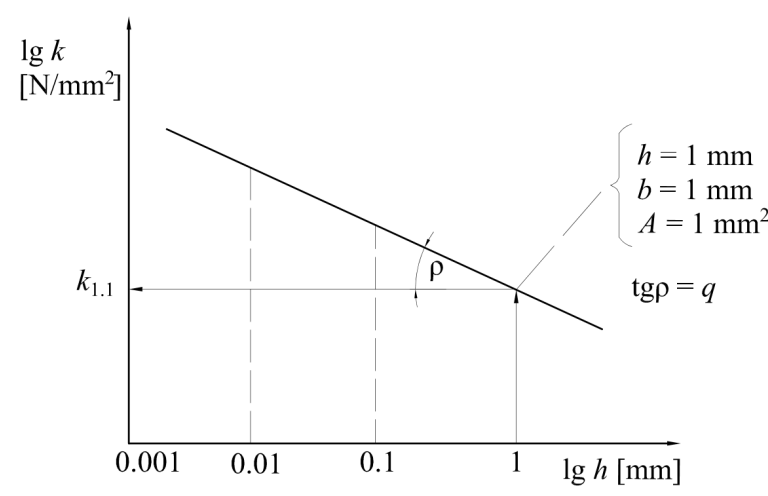

Fig. 4. The main specific cutting force as a function of the chip thickness on a logarithmic scale chart (based on [34])

As the specific cutting force depends strongly on the chip thickness [34] (Fig. 4), Kienzle and Victor determined the main value of the specific cutting force in their model (see Eq. (5)), where $b=1 \mathrm{~mm} ; h=1$ $\mathrm{mm} ; A=1 \mathrm{~mm}^{2}$. 


$$
k_{c}=\frac{k_{c 1.1}}{h^{q_{c}}} .
$$

The cutting force model of Kienzle-Victor for the main cutting force can be seen in Eq. (6) [34]:

$$
F_{c}=k_{c} \cdot A=\frac{k_{c 1.1}}{h^{q c}} \cdot b \cdot h=k_{c 1.1} \cdot h^{1-q_{c}} \cdot b
$$

The Eq. (6) is appropriate for estimating the main cutting force in case of rough turning, where the effect of the nose radius on the chip cross-section is neglected (see Fig. 3).

However, in the case of fine turning, when the chip removal takes places primarily not on the side cutting edge, but also on the nose radius $\left(a>r_{\varepsilon}\right)$ or only on the nose radius $\left(a<<r_{\varepsilon}\right)$, the abovementioned Kienzle-Victor model cannot be used. The geometry of the chip cross-section, shown on Fig. 5, is significantly different, as the removed chip is relevantly smaller than in the case of roughing. Therefore, new parameters must be introduced, instead of chip thickness and width, to characterise the chip cross-section of fine turning.

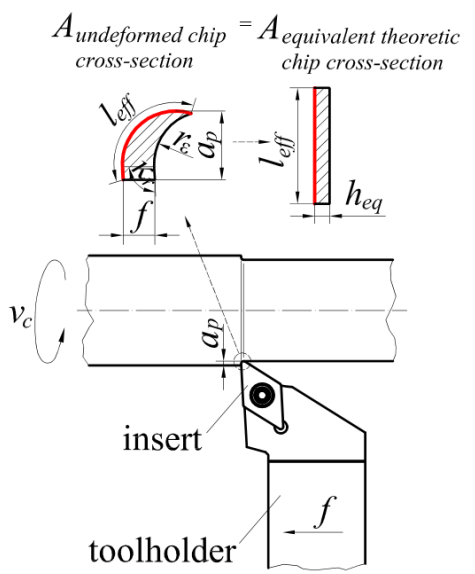

Fig. 5. Chip cross-section in case of fine turning

Cutting on or near the nose radius, using the new parameters of the chip cross-section is well-founded. Theoretical chip width, the so called effective cutting length can be calculated according to Eq. (7) [35].

$$
l_{\text {eff }}=\frac{a_{p}-r_{\varepsilon} \cdot\left(1-\cos \kappa_{r}\right)}{\sin \kappa_{r}}+r_{\varepsilon} \cdot\left(\kappa_{r}+\arcsin \frac{f}{2 \cdot r_{\varepsilon}}\right) .
$$

From the removed cross-section equivalent, chip thickness can be defined (see Eq. (9)).

$$
A=a_{p} \cdot f=l_{e f f} \cdot h_{e q},
$$

$$
h_{e q}=\frac{A}{l_{e f f}}=\frac{a_{p} \cdot f}{l_{e f f}} .
$$

The specific cutting forces (all three components) can be determined by Eq. (10) which is the extended version (for each three direction) of Eq. (4).

$$
k=\frac{F}{A}=\frac{F}{a_{p} \cdot f}=\frac{F}{l_{e f f} \cdot h_{e q}} .
$$

It can be stated that the specific cutting forces depend, not obviously, on the removed chip crosssection (the same cross-section can be resulted by many different set cutting values). In contrast, those can be defined by the geometrical parameters $\left(h_{e q}\right.$ and $\left.l_{\text {eff }}\right)$. That is why the Kienzle-Victor equation extended by Horváth [31] is used, where the specific cutting force for fine turning can be calculated by Eq. (11).

$$
k=C \cdot h_{e q}^{q} \cdot l_{e f f}^{y} .
$$

Furthermore, a contradiction can be found because regarding fine turning technologies a theoretical chip cross-section defined by $l_{\text {eff }}=1 \mathrm{~mm}$ and $h_{e q}=1 \mathrm{~mm}$ does not exist. Moreover, as chip thickness is reduced, the steepness of the increment of specific cutting force is not constant [36] and [37]. A new main value of the specific cutting force is to introduce $\left(k_{1,0.1}\right)$, where $l_{\text {eff }}=1 \mathrm{~mm}$ and $h_{e q}=0.1 \mathrm{~mm}$. In that case $k_{1,0.1}$ characterizing fine turning can be defined according to Eq. (12).

$$
\begin{gathered}
k_{1.0,1}=C \cdot h_{\text {eq }}^{q} \cdot l_{\text {eff }}^{y}=C \cdot 0.1^{q} \cdot 1^{y}=C \cdot 0.1^{q}=C \cdot 10^{-q}, \\
C=\frac{k_{1.0,1}}{0,1^{q}}=\frac{k_{1.0,1}}{10^{-q}}=k_{1.0,1} \cdot 10^{q} .
\end{gathered}
$$

The cutting force model (see Eq. (14)) is determined by using Eqs. (11) and (13) [31]:

$$
F=k \cdot A=k \cdot h_{e q} \cdot l_{e f f}=k_{1.0,1} \cdot 10^{q} \cdot h_{e q}^{1+q} \cdot l_{e f f}^{1+y} .
$$

\subsection{Cutting Studies}

The experiment was built to involve the whole technological spectrum of fine turning. To this end feed was varied in seven $(f=0.03 \mathrm{~mm}$ to $0.15 \mathrm{~mm})$ and depth of cut in three levels $\left(a_{p}=0.25 \mathrm{~mm}\right.$ to $0.7 \mathrm{~mm}$ ). Experimental runs are shown in Table 1 with their set cutting and geometrical parameters.

As a result of the value of tool nose radius $\left(r_{\varepsilon}=0.4 \mathrm{~mm}\right)$ in the case of the highest depth of cut $\left(a_{p}=0.7 \mathrm{~mm}\right)$ the chip removal befalls even on a short part of the side cutting edge. In contrast, at the lowest 
level $\left(a_{p}=0.25 \mathrm{~mm}\right)$ it is only the nose radius that takes place in the chip formation.

Table 1. Experimental runs

\begin{tabular}{|c|c|c|c|c|c|}
\hline $\begin{array}{l}\text { Exp. } \\
\text { runs }\end{array}$ & $\begin{array}{c}a_{p} \\
{[\mathrm{~mm}]}\end{array}$ & $\underset{[\mathrm{mm}]}{f}$ & $\begin{array}{c}l_{e f f} \\
{[\mathrm{~mm}]}\end{array}$ & $\begin{array}{c}h_{e q} \\
{[\mathrm{~mm}]}\end{array}$ & $\begin{array}{c}A \\
{\left[\mathrm{~mm}^{2}\right]}\end{array}$ \\
\hline 1. & 0.25 & 0.03 & 0.493 & 0.015 & 0.0075 \\
\hline 2. & 0.25 & 0.05 & 0.503 & 0.025 & 0.0125 \\
\hline 3. & 0.25 & 0.07 & 0.513 & 0.034 & 0.0175 \\
\hline 4. & 0.25 & 0.09 & 0.523 & 0.043 & 0.0225 \\
\hline 5. & 0.25 & 0.11 & 0.533 & 0.052 & 0.0275 \\
\hline 6. & 0.25 & 0.13 & 0.543 & 0.060 & 0.0325 \\
\hline 7. & 0.25 & 0.15 & 0.554 & 0.068 & 0.0375 \\
\hline 8. & 0.5 & 0.03 & 0.743 & 0.020 & 0.015 \\
\hline 9. & 0.5 & 0.05 & 0.753 & 0.033 & 0.025 \\
\hline 10. & 0.5 & 0.07 & 0.763 & 0.046 & 0.035 \\
\hline 11. & 0.5 & 0.09 & 0.774 & 0.058 & 0.045 \\
\hline 12. & 0.5 & 0.11 & 0.784 & 0.070 & 0.055 \\
\hline 13. & 0.5 & 0.13 & 0.794 & 0.082 & 0.065 \\
\hline 14. & 0.5 & 0.15 & 0.804 & 0.093 & 0.075 \\
\hline 15. & 0.7 & 0.03 & 0.944 & 0.022 & 0.021 \\
\hline 16. & 0.7 & 0.05 & 0.954 & 0.037 & 0.035 \\
\hline 17. & 0.7 & 0.07 & 0.964 & 0.051 & 0.049 \\
\hline 18. & 0.7 & 0.09 & 0.974 & 0.065 & 0.063 \\
\hline 19. & 0.7 & 0.11 & 0.984 & 0.078 & 0.077 \\
\hline 20. & 0.7 & 0.13 & 0.994 & 0.092 & 0.091 \\
\hline 21. & 0.7 & 0.15 & 1.004 & 0.105 & 0.105 \\
\hline
\end{tabular}

Several researchers were studying the connection between cutting speed and the generated forces. It can be stated that the alteration of cutting speed has a negligible effect on cutting forces in comparison to feed and depth of cut [12], [13], [16], [23], [38] to [40]. Cutting tests were carried out with a constant cutting speed in case of each material. The set values are shown in Table 2.

Table 2. Constant cutting speed values for each material

\begin{tabular}{lccc}
\hline Material & $\mathrm{C} 45$ & $\mathrm{KO36}$ & $\mathrm{AS} 12$ \\
\hline$v_{c}[\mathrm{~m} / \mathrm{min}]$ & 300 & 210 & 600 \\
\hline
\end{tabular}

\section{RESULTS}

In the case of all three materials, the cutting force components were measured twice $\left(F_{c}, F_{f}, F_{p}\right.$ - see Fig. 1). The means are shown in Table 3.

\subsection{Investigation of Specific Cutting Forces}

The components of the specific cutting force were determined by Eq. (4). The constant values of the specific cutting force model adapted for fine turning (see Eq. (11)) were calculated by three parametric

Table 3. Mean values of the cutting force components

\begin{tabular}{|c|c|c|c|c|c|c|c|c|c|}
\hline \multirow{2}{*}{$\begin{array}{l}\text { Exp. } \\
\text { runs }\end{array}$} & \multicolumn{3}{|c|}{$\mathrm{C} 45$} & \multicolumn{3}{|c|}{ K036 } & \multicolumn{3}{|c|}{ AS12 } \\
\hline & $F_{c}[\mathrm{~N}]$ & $F_{f}[\mathrm{~N}]$ & $F_{p}[\mathrm{~N}]$ & $F_{c}[\mathrm{~N}]$ & $F_{f}[\mathrm{~N}]$ & $F_{p}[\mathrm{~N}]$ & $F_{c}[\mathrm{~N}]$ & $F_{f}[\mathrm{~N}]$ & $F_{p}[\mathrm{~N}]$ \\
\hline 1. & 41.2 & 32.9 & 41.1 & 41.1 & 35.9 & 58.5 & 7.3 & 2.4 & 3.2 \\
\hline 2. & 50.9 & 36.0 & 50.2 & 53.8 & 37.9 & 60.9 & 10.7 & 3.1 & 4.0 \\
\hline 3. & 63.0 & 39.4 & 57.1 & 68.2 & 38.8 & 62.7 & 14.1 & 3.6 & 4.8 \\
\hline 4. & 70.2 & 42.0 & 63.8 & 75.0 & 42.5 & 66.2 & 16.8 & 4.0 & 5.5 \\
\hline 5. & 78.2 & 45.1 & 66.2 & 83.5 & 45.5 & 74.6 & 18.9 & 4.1 & 5.9 \\
\hline 6. & 88.4 & 49.0 & 71.6 & 92.5 & 50.8 & 76.9 & 21.1 & 4.4 & 6.3 \\
\hline 7. & 100.0 & 52.4 & 75.6 & 103.3 & 51.2 & 79.4 & 24.0 & 4.9 & 7.1 \\
\hline 8. & 70.0 & 72.3 & 44.9 & 75.6 & 82.3 & 56.3 & 14.0 & 5.8 & 2.8 \\
\hline 9. & 95.9 & 81.1 & 54.7 & 102.0 & 93.8 & 59.8 & 21.5 & 7.3 & 3.9 \\
\hline 10. & 125.5 & 89.2 & 63.8 & 128.3 & 102.2 & 62.2 & 28.5 & 8.6 & 4.9 \\
\hline 11. & 142.0 & 93.9 & 73.0 & 155.0 & 107.2 & 65.9 & 34.5 & 9.5 & 5.2 \\
\hline 12. & 160.8 & 103.5 & 82.2 & 170.8 & 110.2 & 67.5 & 39.8 & 10.3 & 5.8 \\
\hline 13. & 183.5 & 108.6 & 87.1 & 196.4 & 113.6 & 70.0 & 44.1 & 10.5 & 6.0 \\
\hline 14. & 198.2 & 114.5 & 92.3 & 222.8 & 118.4 & 74.1 & 48.3 & 10.8 & 6.3 \\
\hline 15. & 90.7 & 92.4 & 40.9 & 105.0 & 137.5 & 44.4 & 19.3 & 8.3 & 2.7 \\
\hline 16. & 124.0 & 109.0 & 51.4 & 145.8 & 169.8 & 49.2 & 29.8 & 11.3 & 3.8 \\
\hline 17. & 167.0 & 122.0 & 59.7 & 195.4 & 184.9 & 51.3 & 37.8 & 13.0 & 4.6 \\
\hline 18. & 185.0 & 134.9 & 70.5 & 219.3 & 197.4 & 53.8 & 45.0 & 14.1 & 5.1 \\
\hline 19. & 216.2 & 148.4 & 80.7 & 265.3 & 208.0 & 55.3 & 51.9 & 14.7 & 5.6 \\
\hline 20. & 246.0 & 154.3 & 89.7 & 293.0 & 215.0 & 58.9 & 58.5 & 14.8 & 5.8 \\
\hline 21. & 278.0 & 162.4 & 94.8 & 315.5 & 225.0 & 64.9 & 67.2 & 15.9 & 5.9 \\
\hline
\end{tabular}


Table 4. The constant values of the specific cutting force model Eq. (11)

\begin{tabular}{cccccccccc}
\hline & \multicolumn{3}{c}{$k_{c}$} & \multicolumn{1}{c}{$k_{f}$} & & \multicolumn{2}{c}{$k_{p}$} \\
\cline { 2 - 10 } & $c_{c}$ & $q_{c}$ & $y_{c}$ & $c_{f}$ & $q_{f}$ & $y_{f}$ & $c_{p}$ & $q_{p}$ & $y_{p}$ \\
\hline C45 & 982 & -0.408 & 0.094 & 268 & -0.764 & 0.591 & 238 & -0.557 & -1.121 \\
\hline K036 & 1193 & -0.390 & 0.260 & 322 & -0.820 & 1.155 & 98 & -0.810 & -1.370 \\
\hline AS12 & 358 & -0.259 & 0.125 & 39 & -0.635 & 0.751 & 22 & -0.442 & -1.542 \\
\hline
\end{tabular}

power function regression. Table 4 shows the materials and the connecting constants.

Regarding the specific cutting force components $\left(k_{c}, k_{p}, k_{f}\right)$, taking the appropriate values from Table 4 and substituting them into Eq. (11) results in a difference within $\pm 10 \%$ between the measured and calculated values, in the case of all three materials.

As regards both components, the main values of the specific cutting forces can be defined within the technological limits of fine turning. That means a theoretical chip cross-section, where $h_{e q}=0.1 \mathrm{~mm}$ and $l_{\text {eff }}=1 \mathrm{~mm}$ (see Table 5). By using these parts, cutting force components can be calculated easily (see Eqs. (15) to (23)).

Table 5. Main values of the specific cutting forces in case of fine turning

\begin{tabular}{cccc}
\hline & C45 & K036 & AS12 \\
\hline$k_{c 1,0.1}$ & 2513 & 2928 & 650 \\
\hline$k_{f 1,0.1}$ & 1556 & 2127 & 168 \\
\hline$k_{p 1,0.1}$ & 858 & 633 & 61 \\
\hline
\end{tabular}

Fig. 6. shows the components of the specific cutting force, as a function of the equivalent chip thickness $\left(h_{e q}\right)$ and the theoretical cutting length $\left(l_{\text {eff }}\right)$ on logarithmic scale charts. In comparison to the Kienzle-Victor model (see Fig. 4), in the case of fine turning, specific cutting force values depend on the thickness of the removed chip; however, the influence of the effective cutting length is also significant (especially regarding feed and thrust force components). Consequently, the Kienzle-Victor equation has to be extended Eq. (11), so the new model takes into consideration both geometrical parameters of the theoretical chip cross-section $\left(h_{e q}\right.$ and $\left.l_{e f f}\right)$.

\subsection{Cutting Force Models}

Having determined the main values of the specific cutting force for fine turning (Tables 4 and 5), the generated forces can be calculated for each material and each direction. The force models are as follows:
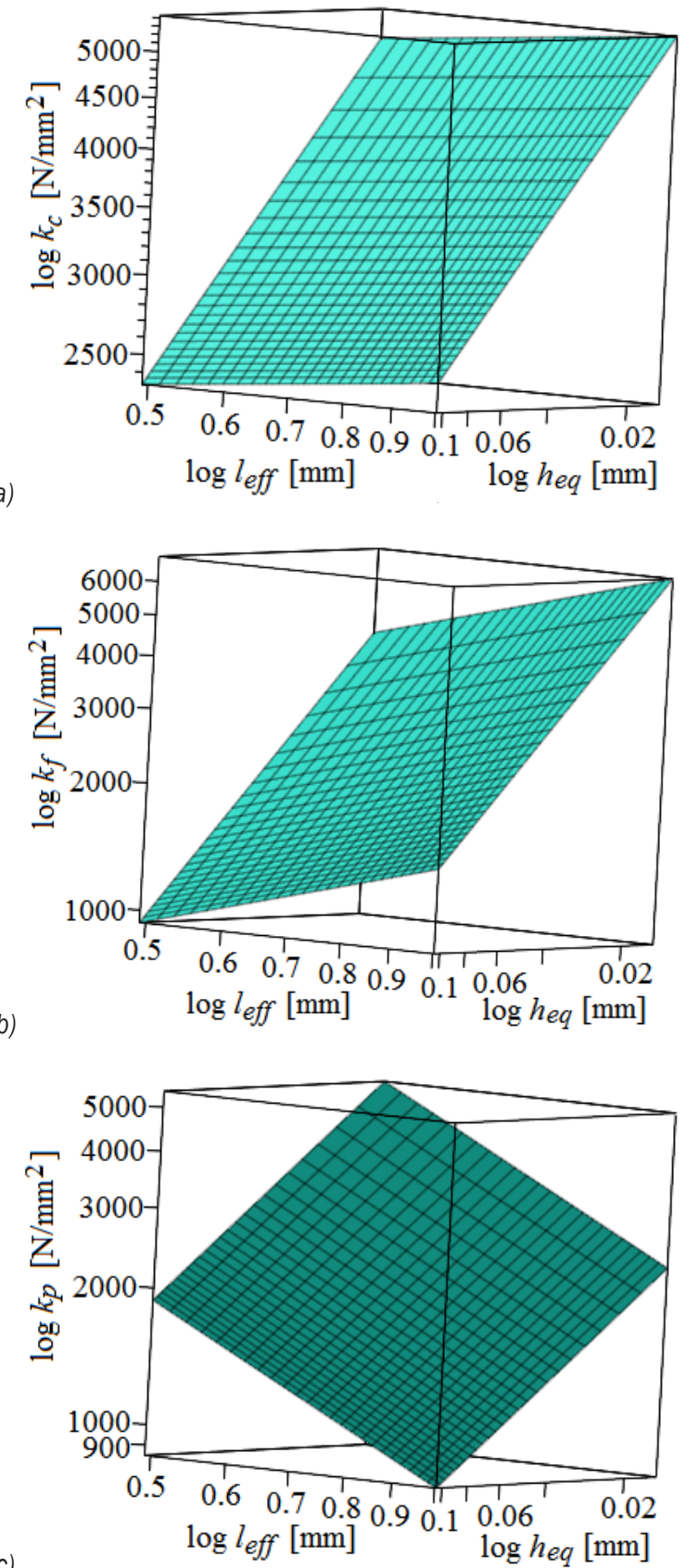

Fig. 6. The specific cutting force components as a function of equivalent chip thickness and effective cutting length (in case of C45); a) in the directions of $\left.F_{c}, b\right)$ in the directions $F_{f}$, and c) in the directions $F_{p}$ 


$$
\begin{aligned}
& F_{c_{-} C 45}=2513 \cdot 10^{-0.408} \cdot h_{e q}^{0.592} \cdot l_{e f f}^{1.094}, \\
& F_{f_{-} C 45}=1556 \cdot 10^{-0.764} \cdot h_{e q}^{0.236} \cdot l_{e f f}^{1.591}, \\
& F_{p_{-} C 45}=858 \cdot 10^{-0.557} \cdot h_{e q}^{0.443} \cdot l_{e f f}^{-0.121}, \\
& F_{c_{-} K O 36}=2928 \cdot 10^{-0.390} \cdot h_{e q}^{0.610} \cdot l_{e f f}^{1.260}, \\
& F_{f_{-} K O 36}=2127 \cdot 10^{-0.820} \cdot h_{e q}^{0.180} \cdot l_{e f f}^{2.155}, \\
& F_{p_{-} K O 36}=633 \cdot 10^{-0.810} \cdot h_{e q}^{0.190} \cdot l_{e f f}^{-0.370}, \\
& F_{c_{-} A S 12}=650 \cdot 10^{-0.259} \cdot h_{e q}^{0.741} \cdot l_{e f f}^{1.125}, \\
& F_{f_{-} A S 12}=168 \cdot 10^{-0.635} \cdot h_{e q}^{0.365} \cdot l_{e f f}^{1.751}, \\
& F_{p_{-} A S 12}=61 \cdot 10^{-0.442} \cdot h_{e q}^{0.558} \cdot l_{e f f}^{-0.542} .
\end{aligned}
$$

\subsection{Examination of the Model}

Fig. 7 shows residuals of the measured and calculated values of the force components. It was stated that the deviations follow normal distribution, and their expected values are nearly zero. Furthermore, each force model (see Eqs. (15) to (23)) provides an adequate accuracy (within a deviation of $10 \%$ ), so those can be applied during the process planning procedure.

\section{CONCLUSION}

In this article, a force model adapted for fine turning was shown in the case of finishing of three widely used materials the technological properties of which are, however, significantly different. About the application of the model the conclusions are as follows:

- $\quad$ in case of fine turning, $h$ chip thickness and $b$ chip width are not proper to characterise the non-deformed chip cross-section, because it is primarily the nose radius that takes place in the chip formation. That is why new geometrical parameters are introduced: $h_{e q}$ equivalent chip thickness and $l_{\text {eff }}$ effective cutting length;

- it was proved that specific cutting forces in case of all three components are affected notably by $l_{\text {eff }}$ and are not only a function of $h_{e q}$ (especially in the
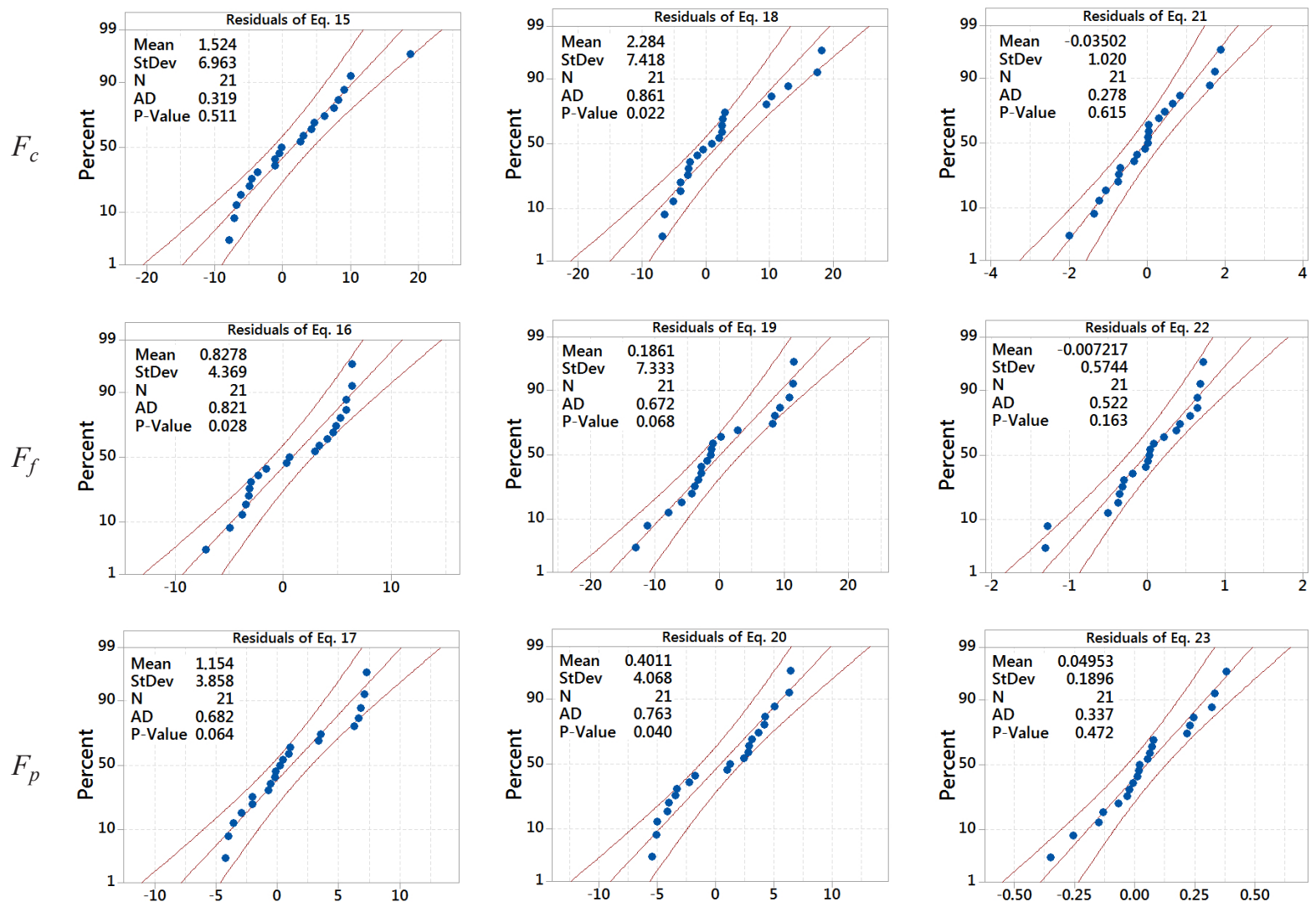

a) Fig. 7. Residuals on normal probability plots

b)

c) 
case of $k_{f}$ and $k_{p}$ ). Consequently, both geometrical parameters are needed in the specific cutting force model (Eq. (11)) despite the Kienzle-Victor equation (the case of bigger chip cross-sections);

- the investigations revealed that specific cutting force components are affected by both theoretical parameters of chip cross-section $\left(h_{e q}\right.$ and $\left.l_{e f f}\right)$. The effect of $l_{\text {eff }}$ was the lowest on $k_{c}$ and was the most influential in case of $k_{p}$ (see Fig. 6);

- it was stated that the model adapted for fine turning forces can be used in the case of materials having technologically significantly different properties. Thus, the application of the equations is independent of the workpiece material;

- $\quad$ since in the case of fine turning the removed chip cross-section cannot be compared with the one used in the Kienzle-Victor model, a novel main value of the specific cutting force $\left(k_{1,0.1}\right)$ was introduced for the technology instead of $k_{1.1}$. The main values of the specific cutting force were determined for each material and each direction $\left(k_{c 1,0.1 C 45}=2513 \mathrm{~N} / \mathrm{mm}^{2} ; k_{f 1,0.1 C 45}=1556 \mathrm{~N} /\right.$ $\mathrm{mm}^{2} ; k_{p 1,0.1 \_C 45}=858 \mathrm{~N} / \mathrm{mm}^{2} ; k_{c 1,0.1 \_K O 36}=2928$ $\mathrm{N} / \mathrm{mm}^{2} ; k_{f 1,0.1 \_K O 36}=2127 \mathrm{~N} / \mathrm{mm}^{2} ; k_{p 1,0.11_{-} K O 36}=$ $633 \mathrm{~N} / \mathrm{mm}^{2} ; k_{c 1,0.1 \_A S 12}=650 \mathrm{~N} / \mathrm{mm}^{2} ; k_{f 1,0.1 \_A S 12}=$ $\left.168 \mathrm{~N} / \mathrm{mm}^{2} ; k_{p 1,0.1 \quad A S 12}=61 \mathrm{~N} / \mathrm{mm}^{2}\right)$;

- based on the specific cutting forces and the parameters of the undeformed chip crosssection $\left(h_{e q}\right.$ and $\left.l_{\text {eff }}\right)$ cutting force models were generated (in case of all three examined materials and each directions) with the help of which the components of the cutting force can be estimated. Moreover, the errors of force models follow normal distribution and their expected values are approximating zero;

- the above-mentioned models are adapted for precision turning when the chip removal process primarily takes place on the tool nose radius. The technological limits of fine turning where the generated force models are applicable is $a_{p}=0.25$ $\mathrm{mm}$ to $0.7 \mathrm{~mm} ; f=0.03 \mathrm{~mm}$ to $0.15 \mathrm{~mm}$;

- the constructed new force model is adapted to estimate the cutting forces in the case of precision turning that is useful in the technological process planning procedure to predict the generated force components with an adequate accuracy.

\section{NOMENCLATURE}

A chip cross-section, [ $\left[\mathrm{mm}^{2}\right]$

$a_{p} \quad$ depth of cut, [mm]

AS12 die-cast eutectic aluminium alloy

$b \quad$ chip width, [mm]
$C, q, y$ empirically defined constants of the specific cutting force model in case of fine turning

C45 non-alloy quality steel

$f$ feed, [mm]

$F \quad$ resultant cutting force, $[\mathrm{N}]$

$F_{c} \quad$ main cutting force, $[\mathrm{N}]$

$F_{f} \quad$ feed force, $[\mathrm{N}]$

$F_{p} \quad$ thrust force, [N]

$h \quad$ chip thickness, $[\mathrm{mm}]$

$h_{e q} \quad$ equivalent chip thickness, [mm]

$k_{c} ; k_{f ;} k_{p}$ specific cutting forces in the directions of $F_{c}, F_{f}, F_{p},\left[\mathrm{~N} / \mathrm{mm}^{2}\right]$

$k_{c 1,0.1}, k_{f 1,0.1}, k_{p 1,0.1}$ main values of the specific cutting force in the directions of $F_{c}, F_{f}, F_{p}$, in case of fine turning, $\left[\mathrm{N} / \mathrm{mm}^{2}\right]$

$k_{c 1.1} \quad$ main value of the specific cutting force (Kienzle-Victor model), [N/ $\left.\mathrm{mm}^{2}\right]$

KO36 austenite stainless steel

$\kappa_{r} \quad$ side cutting angle, $\left[{ }^{\circ}\right]$

$l_{\text {eff }} \quad$ effective cutting length of the edge of the tool, $[\mathrm{mm}]$

PCD polycrystalline diamond

$r_{\varepsilon} \quad$ nose radius of the tool, [mm]

$v_{c} \quad$ cutting speed, $[\mathrm{m} / \mathrm{min}]$

\section{ACKNOWLEDGEMENTS}

Supported by the ÚNKP-16-4/I. New National Excellence Program of the Ministry of Human Capacities, Hungary.

\section{REFERENCES}

[1] Rusinek, R., Wiercigroch, M., \& Wahi, P. (2015). Orthogonal cutting process modelling considering tool-workpiece frictional effect. Procedia CIRP, vol. 31, p. 429-434, D0I:10.1016/j. procir.2015.03.033.

[2] Kulkarni, A.P., Joshi, G.G., Karekar, A., Sargade, V.G. (2014). Investigation on cutting temperature and cutting force in turning AISI 304 austenitic stainless steel using AlTiCrN coated carbide insert. International Journal of Machining and Machinability of Materials, vol. 15, no. 3-4, p. 147-156, D0I:10.1504/IJMMM.2014.060546.

[3] Čep, R., Janásek, A., Sadílek, M., \& Čepová, L. (2012). Tungaloy Ceramic Cutting Tools at Interrupted Machninig. Engineering Review, vol. 32, no. 2, p. 112-118.

[4] Suresh, R., Basavarajappa, S., Samuel, G.L. (2012). Some studies on hard turning of AISI 4340 steel using multilayer coated carbide tool. Measurement, vol. 45. no. 7, p. 18721884, DOI:10.1016/j.measurement.2012.03.024.

[5] López de Lacalle, L.N., Lamikiz, A., Sánchez, J. A., Salgado, M.A. (2004). Effects of tool deflection in the high-speed milling of inclined surfaces. The International Journal of Advanced Manufacturing Technology, vol. 24, no. 9, p. 621-631, D0I: 10.1007/s00170-003-1723-x. 
[6] Cukor, G., Jurković, Z. (2010). Optimization of turning using evolutionary algorithms. Engineering Review, vol. 30, no. 2, p. 1-10.

[7] Singaravel, B., Selvaraj, T. (2015). Optimization of machining parameters in turning operation using combined TOPSIS and AHP method. Tehnički Vjesnik - Technical Gazette, vol. 22, no. 6, p. 1475-1481, D0I:10.17559/TV-20140530140610.

[8] Selvaraj, D.P., Chandramohan, P., Mohanraj, M. (2014). Optimization of surface roughness, cutting force and tool wear of nitrogen alloyed duplex stainless steel in a dry turning process using Taguchi method. Measurement, vol. 49, p. 205215, D0I:10.1016/j.measurement.2013.11.037.

[9] Puh, F., Jurkovic, Z., Perinic, M., Brezocnik, M., \& Buljan, S. (2016). Optimization of machining parameters for turning operation with multiple quality characteristics using Grey relational analysis. Tehnički vjesnik - Technical Gazette, vol. 23, no. 2, p. 377-382, D0l:10.17559/TV-20150526131717.

[10] Hassine, H., Barkallah, M., Bellacicco, A., Louati, J., Riviere, A., Haddar, M. (2015). Multi objective optimization for sustainable manufacturing, application in turning. International Journal of Simulation Modelling, vol. 14, no. 1, p. 98-109, D0l:10.2507/ IJSIMM14(1)9.292.

[11] Karpuschewski, B., Schmidt, K., Beňo, J., Maňková, I., Frohmüller, R., Prilukova, J. (2015). An approach to the microscopic study of wear mechanisms during hard turning with coated ceramics. Wear, vol. 342-343, p. 222-233, DOI:10.1016/j.wear.2015.08.021.

[12] Nayak, M., Sehgal, R. (2015). Effect of tool material properties and cutting conditions on machinability of AISI D6 steel during hard turning. Arabian Journal for Science and Engineering, vol. 40, no. 4, p. 1151-1164, D0l:10.1007/s13369-015-15780 .

[13] El Hakim, M.A., Shalaby, M.A., Veldhuis, S.C., Dosbaeva, G.K. (2015). Effect of secondary hardening on cutting forces, cutting temperature, and tool wear in hard turning of high alloy tool steels. Measurement, vol. 65, p. 233-238, D0l:10.1016/j. measurement.2014.12.033.

[14] Kundrák, J., Mamalis, A.G., Gyani, K., Bana, V. (2011). Surface layer microhardness changes with high-speed turning of hardened steels. The International Journal of Advanced Manufacturing Technology, vol. 53, no. 1, p. 105-112, D0l:10.1007/s00170-010-2840-y.

[15] Chen, T., Li, S., Han, B., Liu, G. (2014). Study on cutting force and surface micro-topography of hard turning of GCr15 steel. The International Journal of Advanced Manufacturing Technology, vol. 72, no. 9, p. 1639-1645, D0l:10.1007/ s00170-014-5778-7.

[16] Meddour, I., Yallese, M. A., Khattabi, R., Elbah, M., Boulanouar, L. (2015). Investigation and modeling of cutting forces and surface roughness when hard turning of AISI 52100 steel with mixed ceramic tool: cutting conditions optimization. The International Journal of Advanced Manufacturing Technology, vol. 77, no. 5, p. 1387-1399, D0l:10.1007/s00170-0146559-z.

[17] Wojciechowski, S., Chwalczuk, T., Twardowski, P., Krolczyk, G.M. (2015). Modeling of cutter displacements during ball end milling of inclined surfaces. Archives of Civil and Mechanical
Engineering, vol. 15, no, 4, p. 798-805, D0l:10.1016/j. acme.2015.06.008.

[18] Wojciechowski, S., Maruda, R.W., Nieslony, P., Krolczyk, G.M. (2016). Investigation on the edge forces in ball end milling of inclined surfaces. International Journal of Mechanical Sciences, vol. 119, p. 360-369, D0l:10.1016/j. ijmecsci.2016.10.034.

[19] Wojciechowski, S., Twardowski, P., Pelic, M., Maruda, R.W., Barrans, S., Krolczyk, G.M. (2016). Precision surface characterization for finish cylindrical milling with dynamic tool displacements model. Precision Engineering, vol. 46, p. 158165, D0I:10.1016/j.precisioneng.2016.04.010.

[20] Zębala, W., Kowalczyk, R. (2015). Estimating the effect of cutting data on surface roughness and cutting force during WC-Co turning with PCD tool using Taguchi design and ANOVA analysis. The International Journal of Advanced Manufacturing Technology, vol. 77, no. 9, p. 2241-2256, D0l:10.1007/ s00170-014-6382-6.

[21] Mata, F., Hanafi, I., Beamud, E., Khamlichi, A., Jabbouri, A. (2012). Modelling of machining force components during turning of PEEK CF30 by TiN coated cutting tools using artificial intelligence. International Journal of Machining and Machinability of Materials, vol. 11, no. 3, p. 263-279, DOI:10.1504/IJMMM.2012.046885.

[22] Hanafi, I., Khamlichi, A., Cabrera, F.M., López, P.J.N., Jabbouri, A. (2012). Fuzzy rule based predictive model for cutting force in turning of reinforced PEEK composite. Measurement, vol. 45, no. 6, p. 1424-1435, D0l:10.1016/j. measurement.2012.03.022.

[23] Fetecau, C., Stan, F. (2012). Study of cutting force and surface roughness in the turning of polytetrafluoroethylene composites with a polycrystalline diamond tool. Measurement, vol. 45, no. 6, p. 1367-1379, D0I:10.1016/j.measurement.2012.03.030.

[24] Joardar, H., Das, N.S., Sutradhar, G., Singh, S. (2014). Application of response surface methodology for determining cutting force model in turning of LM6/SiCP metal matrix composite. Measurement, vol. 47, p. 452-464, D0I:10.1016/j. measurement.2013.09.023.

[25] Çolak, 0. (2014). Optimization of machining performance in high-pressure assisted turning of Ti6Al4V alloy. Strojniški vestnik - Journal of Mechanical Engineering, vol. 60, no. 10, p. 675-681, D0l:10.5545/sv-jme.2013.1079.

[26] de Agustina, B., Bernal, C., Camacho, A.M., Rubio, E.M. (2013). Experimental analysis of the cutting forces obtained in dry turning processes of UNS A97075 aluminium alloys. Procedia Engineering, vol. 63, p. 694-699, D0l:10.1016/j. proeng.2013.08.248.

[27] Horváth, R., Drégelyi-Kiss, Á., Mátyási, Gy. (2014). Application of RSM method for the examination of diamond tools. Acta Polytechnica Hungarica, vol. 11, no. 2, p. 137-147, DOl:10.12700/APH.11.02.2014.02.8.

[28] Horváth, R., Drégelyi-Kiss, Á. (2015). Analysis of surface roughness of aluminum alloys fine turned: United phenomenological models and multi-performance optimization. Measurement, vol. 65, p. 181-192, D0l:10.1016/j.measurement.2015.01.013.

[29] Horváth, R., Czifra, Á., Drégelyi-Kiss, Á. (2015). Effect of conventional and non-conventional tool geometries to 
skewness and kurtosis of surface roughness in case of fine turning of aluminium alloys with diamond tools. The International Journal of Advanced Manufacturing Technology, vol. 78, no.1, p. 297-304, D0l:10.1007/s00170-014-6642-5.

[30] Horváth, R., Pálinkás, T., Mátyási, G., Drégelyi-Kiss, Á.G. (2017). The design, calibration and adaption of a dynamometer for fine turning. International Journal of Machining and Machinability of Materials, vol. 19, no. 1, p. 1-16, D0I:10.1504/IJMMM.2017.081183.

[31] Horváth, R. (2015). A New Model for Fine Turning Forces. Acta Polytechnica Hungarica, vol. 12, no. 7, p. 109-128, DOI:10.12700/APH.12.7.2015.7.7.

[32] Venkatesan, K., Radhakrishnan, R., Kuppan, P. (2014). A review on conventional and laser assisted machining of aluminium based metal matrix composites. Engineering Review, vol. 34, no. 2, p. 75-84.

[33] Kundrák, J., Gyáni, K., Deszpoth, I., Sztankovics, I. (2014). Some topics in process planning of rotational turning. Engineering Review, vol. 34, no. 1, p. 23-32.

[34] Kienzle, O., Victor, H. (1957). Spezifische schnittkräfte bei der metallbearbeitung, Werkstattstechnik und Maschinenbau, vol. 47, no. 5, p. 224-225.

[35] Bus, C., Touwen, N.A.L., Veenstra, P.C., Van Der Wolf, A.C.H. (1971). On the significance of equivalent chip thickness. Annals of the CIRP, vol. 19, p. 121-124.
[36] Biró, I., Czampa, M., Szalay, T. (2015). Experimental model for the main cutting force in face milling of a high strength structural steel. Periodica Polytechnica Engineering, vol. 59, no. 1, p. 8-15, Dol:10.3311/PPme.7516.

[37] Biró, I., Szalay, T. (2016). Extension of empirical specific cutting force model for the process of fine chip-removing milling. The International Journal of Advanced Manufacturing Technology, vol. 88, no. 9, p. 2735-2743, D0l:10.1007/ s00170-016-8957-x.

[38] Aouici, H., Yallese, M.A., Chaoui, K., Mabrouki, T., Rigal, J. (2012). Analysis of surface roughness and cutting force components in hard turning with CBN tool: Prediction model and cutting conditions optimization. Measurement, vol. 45, no. 3, p. 344-353, D0I:10.1016/j.measurement.2011.11.011.

[39] Gokkaya, H., Taskesen, A. (2008). The effects of cutting speed and feed rate on Bue-Bul formation, cutting forces and surface roughness when machining AA6351 (T6) Alloy. Strojniški vestnik - Journal of Mechanical Engineering, vol. 54, no. 7-8, p. 521-530.

[40] Velchev, S., Kolev, I., Ivanov, K. (2009). Research on the influence of the cutting speed on the specific cutting force during turning. Strojniški vestnik - Journal of Mechanical Engineering, vol. 55, no. 6, p. 400-405. 